\title{
In vivo T-cell dynamics during immune reconstitution after hematopoietic stem cell gene therapy in adenosine deaminase severe combined immune deficiency
}

\author{
Silvia Selleri, PhD, ${ }^{a}$ Immacolata Brigida, MSc, ${ }^{\text {a,d }}$ Miriam Casiraghi, RCN, ${ }^{\text {a,b }}$ Samantha Scaramuzza, PhD, ${ }^{a, c}$ \\ Barbara Cappelli, MD, ${ }^{b}$ Barbara Cassani, PhD, ${ }^{a, c}$ Francesca Ferrua, MD, ${ }^{b}$ Memet Aker, MD, ${ }^{f}$ Shimon Slavin, MD, \\ Alessia Scarselli, MD, ${ }^{e}$ Caterina Cancrini, MD, ${ }^{e}$ Sarah Marktel, MD, ${ }^{b}$ Maria Grazia Roncarolo, MD, a,b and \\ Alessandro Aiuti, MD, $\mathbf{P h D}^{\mathbf{a}, \mathbf{b}, \mathbf{e}} \quad$ Milan and Rome, Italy, and Jerusalem, Israel
}

Background: Gene therapy (GT) with hematopoietic stem cells is a promising treatment for inherited immunodeficiencies. Objectives: Limited information is available on the relative contribution of de novo thymopoiesis and peripheral expansion to T-cell reconstitution after GT as well as on the potential effects of gene transfer on hematopoietic stem cells and lymphocyte replicative lifespan. We studied these issues in patients affected by adenosine deaminase severe combined immune deficiency after low-intensity conditioning and reinfusion of retrovirally transduced autologous $\mathrm{CD34}^{+}$cells. Methods: Immunophenotype, proliferative status, telomere length, and T-cell receptor excision circles were investigated at early and late time points (up to 9 years) after GT treatment. Control groups consisted of pediatric healthy donors and patients undergoing allogeneic bone marrow transplantation (BMT). Results: We observed no telomere shortening in the bone marrow compartment and in granulocytes, whereas peripheral blood naive $T$ cells from both GT and BMT patients showed a significant reduction in telomere length compared with healthy controls. This was in agreement with the presence of a high fraction of actively cycling naive and memory $T$ cells and lower T-cell receptor excision circles.

Conclusion: These data indicate that T-cell homeostatic expansion contributes substantially to immune reconstitution, like BMT, and is not associated with senescence in the stem cell compartment. (J Allergy Clin Immunol 2011;127:1368-75.)

Key words: Gene therapy, ADA-SCID, senescence, cell cycle, immune reconstitution

\footnotetext{
From ${ }^{a}$ the San Raffaele Telethon Institute for Gene Therapy and ${ }^{b}$ the Pediatric Immunohematology and Bone Marrow Transplantation Unit, San Raffaele Scientific Institute, Milan; 'Istituto Clinico Humanitas, Milan; 'the University of Rome "Tor Vergata," and ethe Department of Pediatrics, University of Rome "Tor Vergata," Children's Hospital Bambino Gesù; and ${ }^{\mathrm{f}}$ Hadassah University Hospital, Jerusalem.

Supported by Fondazione Telethon and grants from the independent drug research program of the Italian Medicines Agency (AIFA; FARM5JRXRM; to A.A.), the European Commission (CLINIGENE LSHB-CT2006-018933 and CEL-PID HEALTH-F52010-261387 to A.A.), and the Italian Ministero della Salute (to C.C.)

Disclosure of potential conflict of interest: S. Selleri, M. Casiraghi, S. Scaramuzza, B Cappelli, B. Cassani, F. Ferrua, A. Scarselli, C. Cancrini, S. Marktel, M. Grazia Roncarolo, and A. Aiuti have received research support from the Fondazione Telethon and the European Community. The rest of the authors have declared that they have no conflict of interest.

Received for publication August 18, 2010; revised March 1, 2011; accepted for publication March 2, 2011

Available online April 7, 2011

Reprint requests: Alessandro Aiuti, MD, PhD, HSR-TIGET, Via Olgettina 58, 20132 Milano, Italy. E-mail: aiuti.alessandro@ hsr.it.

0091-6749/\$36.00

(C) 2011 American Academy of Allergy, Asthma \& Immunology

doi:10.1016/j.jaci.2011.03.004
}

\author{
Abbreviations used \\ ADA: Adenosine deaminase \\ BM: Bone marrow \\ BMT: Bone marrow transplantation \\ FITC: Fluorescein isothiocyanate \\ GT: Gene therapy \\ GVHD: Graft-versus-host disease \\ HSC: Hematopoietic stem cell \\ MNC: Mononuclear cell \\ PB: Peripheral blood \\ qPCR: Quantitative polymerase chain reaction \\ SCID: Severe combined immune deficiency \\ TCR: T-cell receptor \\ TEMRA: T effector memory CD45RA ${ }^{+}$ \\ TREC: T-cell receptor excision circle
}

Autologous transplant of hematopoietic stem cell (HSCs) corrected by ex vivo gene transfer has been investigated as an alternative therapeutic approach to allogeneic bone marrow transplantation (BMT) for primary immunodeficiencies. Long-term immune reconstitution has been achieved in gene therapy (GT) trials for severe combined immunodeficiency (SCID) caused by IL-2 receptor $\gamma^{1-3}$ or adenosine deaminase (ADA) deficiency. ${ }^{4-6}$ In patients with ADA-SCID, transplant of retrovirally transduced $\mathrm{CD} 4^{+}$cells after low-intensity conditioning has resulted in longterm engraftment of multilineage $\mathrm{HSCs}^{7}$ with correction of metabolic and immunologic defects. ${ }^{4,8}$

After BMT or in lymphopenic conditions (ie, resulting from genetic or acquired immunodeficiencies or infections), the T-cell compartment can be sustained by (1) homeostatic proliferation of pre-existing T-cell clones, ${ }^{9-11}$ (2) de novo thymopoiesis, or (3) extrathymic differentiation. ${ }^{12}$ After BMT, the reconstitution of the peripheral $\mathrm{T}$ cells is mainly driven by memory cells, particularly at early follow-up, in both pediatric and adult recipients. ${ }^{13-15}$ There is limited information on the relative contribution of the different T-cell subsets and the various mechanisms of differentiation during the T-cell pool reconstitution after GT treatment.

Despite evidence of very long-term engraftment, senescence of the newly reconstituted hematopoietic cells as a result of the replicative demand imposed on donor HSCs and mature cells has been proposed as a potential threat to the successful outcome of BMT. $^{16-18}$ Because autologous stem/progenitor cells are expanded short-term ex vivo with cytokines before reinfusion, ${ }^{5} \mathrm{GT}$ may result in an increased senescence of the reconstituting cells.

To investigate the dynamic of T-cell reconstitution after GT, we performed a detailed analysis focused on the cell cycle and 
senescence status of the different cell subsets, referring to a group of pediatric patients undergoing allogeneic BMT and healthy children as controls. Our results reveal that homeostatic proliferation represents a substantial mechanism of T-cell repopulation in early phases after GT, like allogeneic BMT, resulting in telomere shortening and T-cell receptor excision circle (TREC) content dilution in the naive T-cell pool compared with pediatric controls. However, we did not find evidence of senescence in the progenitor cell compartment after treatment.

Our data give new insight of the role of homeostatic expansion after GT and confirm this treatment as a valid alternative to BMT for ADA-SCID and possibly for other genetic immunodeficiencies.

\section{METHODS}

\section{Samples}

The research has been conducted on biological specimens from patients with ADA-SCID treated with GT, pediatric patients who underwent BMT, and healthy pediatric and adult subjects. The ADA-SCID HSC-GT clinical trials were approved by the San Raffaele Scientific Institute and National Authorities and registered at ClinicalTrials.gov (nos. NCT00598481 and NCT00599781). Seven patients with ADA-SCID have been described previously $^{4}$; the other 5 displayed typical early onset and were enrolled after failure or unavailability of long-term polyethylene glycol-ADA and were treated between 0.5 and 6.2 years of age (A. Aiuti, unpublished data). Patients received a single infusion of autologous $\mathrm{CD} 34^{+}$cells transduced with GIADAl vector after busulfan infusion ( $4 \mathrm{mg} / \mathrm{kg}$ intravenously). None of the patients received polyethylene glycol-ADA after GT. Peripheral blood (PB) and BM samples from patients with ADA-SCID, patients undergoing BMT, or healthy donors, and umbilical cord blood were collected and used on informed consent for research purposes in agreement with the rules defined by the San Raffaele Hospital (Milan, Italy) and Bambino Gesù Pediatric Hospital (Rome, Italy) Ethical Committees. Permission from healthy donors' or patients' parents/guardians was obtained. The age range of pediatric and adult healthy controls was 1 to 5 years and 20 to 60 years, respectively.

The pediatric BMT group was composed of 16 patients with different diagnoses pretransplant (see this article's Table E1 in the Online Repository at www.jacionline.org). All patients underwent BMT from an HLA-identical donor. Ten patients underwent myeloablative conditioning before transplant, ${ }^{19,20}$ 2 received reduced intensity regimens, and 4 patients with SCID were not conditioned. At the moment of the analysis, none of them was experiencing graft-versus-host disease (GVHD) except 1 (chronic GVHD limited to the oral cavity). We divided both GT and BMT groups into early ( $<2$ years) and late ( $>2$ years) follow-up (Table E1) to distinguish between early and late phases of immune reconstitution.

\section{Proliferation and cell cycle analysis}

Blood samples were stained with antibodies anti-CD4 or CD8 phycoerythrin-Cy7, CD62L-phycoerythrin, CD45RA-PerCp-Cy5.5, and CD45RO-APC (all from Becton Dickinson, San Diego, Calif, except the anti-CD45RA-PerCpCy5.5, obtained from Biolegend, San Diego, Calif). After red blood cell lysis, cell cycle analysis was performed by combining Ki67 intracellular staining ${ }^{21,22}$ and the DNA-specific dye Vybrant Violet (Invitrogen, Carlsbad, Calif). Details about the staining can be found in this article's Methods in the Online Repository at www.jacionline.org. Samples were analyzed with a BD-LSR II Flow Cytometer (Becton Dickinson).

\section{T-cell immunophenotypic analysis}

PBMCs were stained with the following antibodies (all from Becton Dickinson): CD3-PerCp, T-cell receptor (TCR) $-\gamma \delta$-fluorescein isothiocyanate (FITC), CD56-APC, CD8 $\alpha$-PE-Cy7, CD4-PE or CD3-PerCp, TCR- $\gamma \delta-F I T C$, CD56-APC, CD8 $\alpha$-PE-Cy7, and CD8 $\beta$-PE. For the identification of the $\mathrm{CD} 8 \alpha \alpha$ subset, we referred to the gating strategy described by Konno et al. ${ }^{23}$

\section{Telomere length quantification}

Telomere length quantification was performed by the quantitative polymerase chain reaction (qPCR) approach based on a previously established method, ${ }^{24}$ using $36 \mathrm{~B} 4$ as normalizing gene. Details about the primers sequences and amplification conditions are available in the Methods in the Online Repository.

\section{Isolation of different peripheral blood cell subsets}

After Ficoll-Hypaque mononuclear cell (MNC) separation, $\mathrm{CD}^{+}$, naive, and memory $\mathrm{T}$ cells and $\mathrm{CD} 15^{+}$cells were purified with magnetic bead isolation. For details, see the Methods in the Online Repository.

\section{TREC content analysis and quantification of vector- transduced cells}

DNA extracted from naive and memory $\mathrm{T}$ cells was tested for the quantification of recent thymic emigrants by qPCR, using specific primers for TREC amplification, as described. ${ }^{25}$ Quantification of vector containing cells was performed as described. ${ }^{5}$ All qPCRs were run in a 7900 Fast Real Time PCR System (Applied Biosystems, Carlsbad, Calif).

\section{Statistical analysis}

For statistical data analysis, we applied a 2-tailed Mann-Whitney test considering the data set significantly different according to a $P<.05$ : $* P<.05 ; * * P<.005 ; * * * P<.001$

In all the graphs, median values are shown. In the box and whiskers representation, median and interquartile range are shown. Data were analyzed with the Graph-Pad Prism program, version 4.02 (Graph Pad Software, La Jolla, Calif).

\section{RESULTS \\ Contribution of different T-cell subsets to immune reconstitution after GT}

We measured the proportion of naive, central memory, effector memory, and T effector memory CD45RA ${ }^{+}$(TEMRA) ${ }^{26}$ cells in both $\mathrm{CD} 4^{+}$and $\mathrm{CD}^{+}{ }^{+} \mathrm{PB}$ T-cell subsets in GT-treated patients, using as controls adult or pediatric healthy donors and pediatric patients undergoing allogeneic HLA-identical BMT (see this article's Fig E1 in the Online Repository at www.jacionline.org; Table E1). We found that phenotypically naive (CD45RO $\left.\mathrm{CD} 4 \mathrm{RA}^{+} \mathrm{CD}^{-} 2 \mathrm{~L}^{+}\right) \mathrm{CD}^{+}$and $\mathrm{CD} 8^{+}$cells were present at both early ( $<2$ years) and late ( $>2$ years) follow-up after GT and were significantly reduced compared with age-matched controls, but in the range of adult healthy donors (Fig 1). In the early phase after treatment, GT patients displayed a higher proportion of naive $\mathrm{CD}^{+}$and $\mathrm{CD} 8^{+}$cells compared with BMT patients, whereas no significant differences were observed at later time points. The main circulating $\mathrm{CD} 4^{+}$T-cell subsets after GT and BMT were represented by central memory $\left(\mathrm{CD} 45 \mathrm{RO}^{+} \mathrm{CD}^{+} 5 \mathrm{RA}^{-} \mathrm{CD} 62 \mathrm{~L}^{+}\right)$and effector memory $\left(\mathrm{CD} 45 \mathrm{RO}^{+} \mathrm{CD}^{+} 5 \mathrm{RA}^{-} \mathrm{CD}^{-} \mathrm{L}^{-}\right)$cells. $\mathrm{CD} 4^{+}$and $\mathrm{CD}^{+}{ }^{+}$TEMRA cells $\left(\mathrm{CD} 45 \mathrm{RO}^{-} \mathrm{CD} 45 \mathrm{RA}^{+} \mathrm{CD}^{-} \mathrm{L}^{-}\right)$showed a wide variability, with no difference among the groups. Absolute counts of PB lymphocytes and $\mathrm{CD}^{+}$cells improved significantly in GT patients at later follow-up (see this article's Fig $\mathrm{E} 2$ in the Online Repository at www.jacionline.org). $\mathrm{CD}^{+}$ and naive $\mathrm{CD}^{+}$cell counts were lower than the whole HLAidentical BMT group but not significantly different from the ADA-SCID subgroup. PCR analyses for gene-corrected cells confirmed that both naive and memory cells in GT-treated patients were positive for the vector and coexisted with a population of untransduced cells. In both groups, the frequency of 


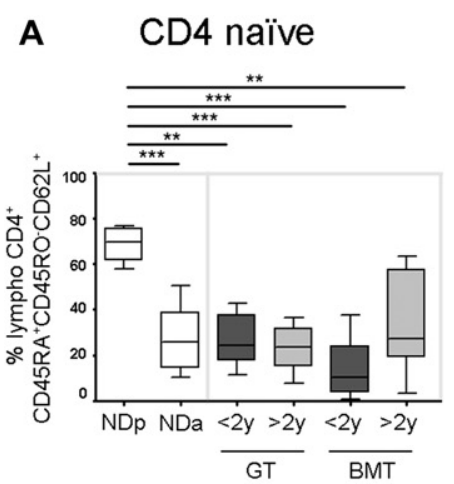

E

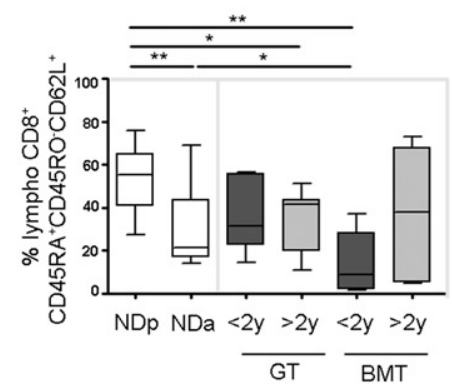

B

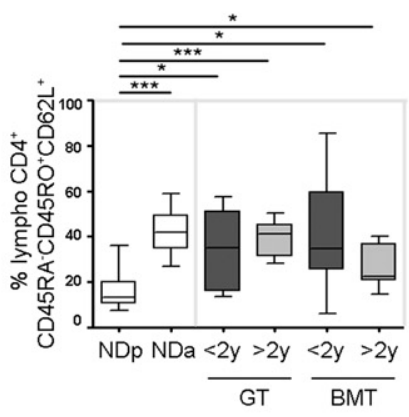

$\mathbf{F}$

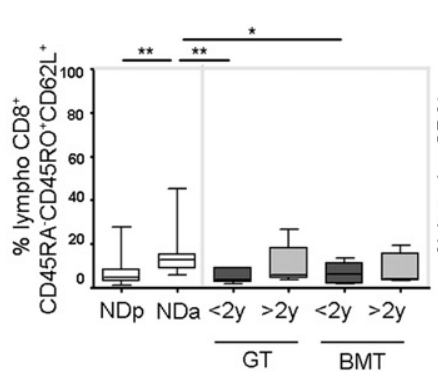

C

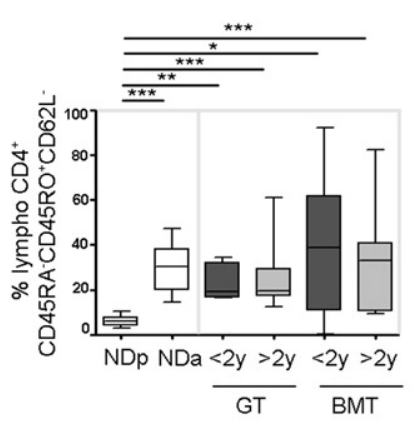

G
D CD4 TEMRA

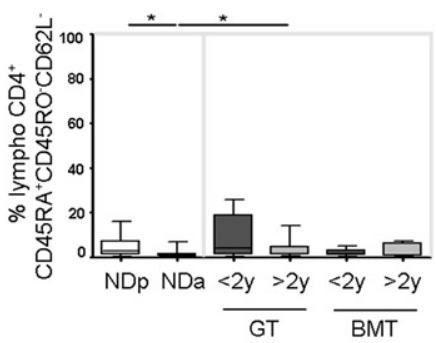

H

CD8 TEMRA

FIG 1. Different contributions of naive, central memory $(C M)$, effector memory (EM), and TEMRA cells to immune reconstitution. The percentage of the different T-cell subsets gated on both the CD4 (A-D) and CD8 (E-H) compartments is shown. Data refer to pediatric normal donors (NDp), adult normal donors (NDa), GT-treated patients, and allogeneic BMT pediatric patients at early (dark gray) and late (light gray) follow-up. Normal donors, $n=11 ; \mathrm{GT}<2$ years $(\mathrm{n}=5) ; \mathrm{GT}>2$ years $(\mathrm{n}=9)$; BMT < 2 years $(\mathrm{n}=7) ; \mathrm{BMT}$ $>2$ years $(n=7)$.

ADA-containing cells increased at a later time, with a stronger selective advantage for vector-positive memory $T$ cells over untransduced cells (see this article's Fig E3 in the Online Repository at www.jacionline.org).

Among less represented T-cell subsets, we found no differences among the distribution of $\mathrm{CD} 8 \alpha \alpha, \mathrm{CD} 8 \alpha^{+} \beta^{\text {low }}, \mathrm{CD} 8 \alpha^{+} \beta^{\text {high }}$ (Fig 2, A), whereas the percentage of $\mathrm{CD} 4^{+} \mathrm{CD} 8^{+} \mathrm{CD} 3^{+}$cells, described as increased in elderly subjects, ${ }^{27}$ was increased 2-fold in the GT group compared with pediatric controls and BMT patients (Fig 2, B). Moreover, a significant increase in the percentage of $\mathrm{CD} 3^{+} \mathrm{TCR}-\gamma \delta$ cells was detected in the GT group, both in the $\mathrm{CD}^{-} \mathrm{CD}^{-}$(Fig 2,C) and in the $\mathrm{CD}^{+}{ }^{+} \mathrm{CD}^{+} 6^{+}$(activated) cell subsets (Fig 2,D).

\section{Cell cycling in naive and memory $T$ cells is increased in the early phase after GT}

We performed a cell cycle analysis in both the $\mathrm{CD} 4^{+}$and $\mathrm{CD} 8^{+}$ compartments by measuring the percentage of cells expressing the G1 phase marker Ki67 (Fig E1). At early follow-up, a significantly higher proportion of cycling cells was observed in $\mathrm{CD}^{+}{ }^{+}$ cell-naive and central memory cell subsets from both GT and BMT groups compared with controls (Fig 3, $A$ and $B$ ), and a tendency was observed also in $\mathrm{CD}^{+}{ }^{+}$-naive and central memory cells (Fig 3, $E$ and $F$ ). Naive cycling cells decreased in frequency at later time points in both GT and BMT groups (Fig 3, $A$ and $E$; see this article's Fig E4 in the Online Repository at www. jacionline.org), although not all patients reached the controls' levels. In the $\mathrm{CD}^{+}{ }^{+}$effector memory compartment, we observed a similar pattern at early and late time points, whereas cycling cells $\mathrm{CD}^{+}$effector memory and TEMRA cell subsets were more dispersed (Fig 3, $C, D, G, H$ ).

We did not observe any statistically significant difference in the percentage and in the absolute number of cycling cells between the GT and the BMT groups (see this article's Table E2 in the Online Repository at www.jacionline.org). Our data indicate that the increased cell cycling in the naive compartment at early time points and its persistence at low but detectable levels represent an important mechanism to sustain homeostasis of the peripheral blood T-cell compartment after GT. Analysis of the S/G2/M phases across the different study groups and the different cellular populations did not show any significant difference, as shown in this article's Fig E5 in the Online Repository at www. jacionline.org.

Next, we measured TREC content by qPCR in sorted naive T cells. The number of TRECs was significantly lower in GT and BMT patients compared with healthy pediatric patients, in agreement with the increased cellular turnover of the naive compartment (Fig 4).

\section{Telomere length after GT is shortened in naive $T$ cells but not in the BM compartment and granulocytes}

As shown in Fig 5, $A$, no difference in the median telomere length of BM MNC from the GT and BMT groups was observed 
A

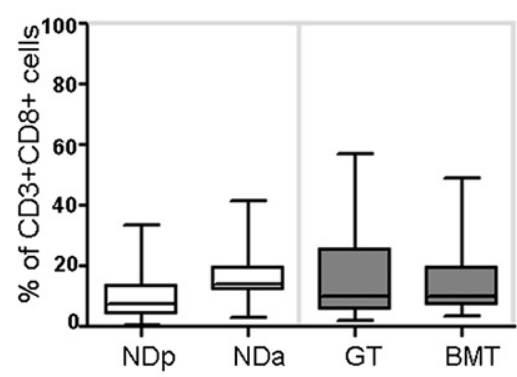

C

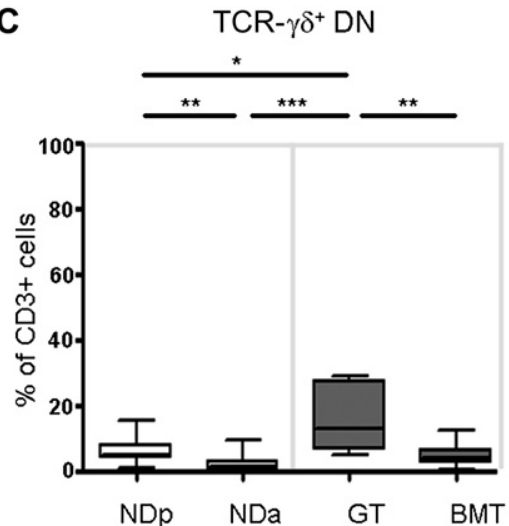

B
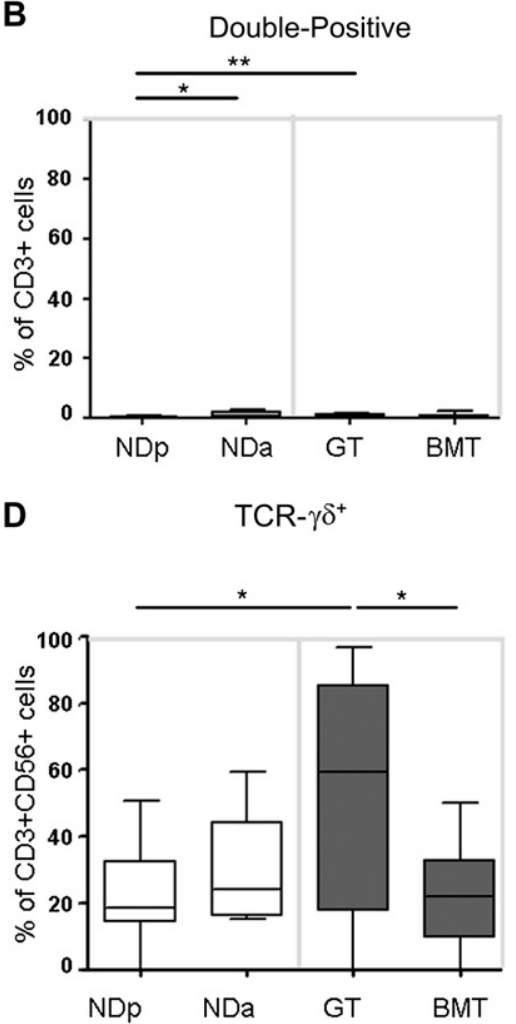

FIG 2. Analysis of $C D 8 \alpha \alpha$ and TCR- $\gamma \delta$ expression. $D N$, Double negative; $N D a$, adult normal donors $(\mathrm{n}=10)$; $N D p$, pediatric normal donors $(\mathrm{n}=12) ; G T$, GT-treated patients $(\mathrm{n}=11$ in $\mathbf{A}, 9$ in $\mathbf{B}$ and $\mathbf{C}, 12$ in $\mathbf{D}) ; B M T$, allogeneic BMT patients $(n=15)$.

with respect to healthy controls. Moreover, $\mathrm{CD} 15^{+}$myeloid cells isolated from the PB and BM, which should reflect changes at the level of progenitor cells, showed similar telomere length in both treated and control groups (Fig 5, B and $C$ ). As expected on the basis of the different age of the subjects, pediatric and adult granulocytes displayed shorter telomeres than those derived from umbilical cord blood cells (Fig 5, C).

T cells from GT patients showed a reduced telomere length than pediatric controls, in the range of BMT-treated patients and adult controls (Fig 5, D). Because this could reflect a different proportion of naive and memory cells within the samples, we measured telomere length in sorted naive $\mathrm{CD}^{+}{ }^{+} \mathrm{CD} 45 \mathrm{RA}^{+} \mathrm{CD}_{45 \mathrm{RO}^{-}}$and memory $\mathrm{CD}^{+}{ }^{+} \mathrm{CD} 45 \mathrm{RA}^{-} \mathrm{CD} 45 \mathrm{RO}^{+}$T cells (Fig 6). As expected, naive cells displayed longer telomeres than memory cells in all groups, and naive $\mathrm{T}$ cells obtained from healthy pediatric subjects showed longer telomeres compared with adult-derived cells. However, telomere length in naive $\mathrm{T}$ cells from BMT and GT patients was significantly shortened compared with naive cells isolated from pediatric controls, showing a length similar to that in adult controls.

\section{DISCUSSION}

The goal of the current work was to deepen our knowledge of the in vivo dynamics of hematopoietic cells during immune reconstitution after autologous transplant of gene-corrected CD34 ${ }^{+}$ cells. Our data show that the recovery of the peripheral T-cell compartment after HSC GT for ADA-SCID is driven by both naive and memory cells, to an extent comparable to what is observed in our age-matched cohort of patients undergoing allogeneic BMT and in previous reports in pediatric and adult BMT recipients. ${ }^{13-15}$ Our cohort of pediatric BMT patients was heterogeneous and included only a minority of patients with ADA-SCID. Nevertheless, we did not find statistically significant differences within this cohort by comparing the absolute number of lymphocytes or T-cell subsets counts with respect to conditioning or diagnosis (data not shown; Fig E2). After GT, immune reconstitution occurs at a slower pace compared with that of the control BMT group ${ }^{4,28}$ (see also Fig E2). This is in part expected because GT patients received an infusion of purified $\mathrm{CD} 34^{+}$cells, whereas in our control group the HLA-identical graft was T-cell-replete. Indeed, in the early phase posttransplant, the percentage of naive CD4 and CD8 cells was higher after GT than BMT, whereas CD4 and CD8 effector memory cells were more represented in BMT patients than GT patients. Nevertheless, memory cells were also overrepresented in GT patients, similar to what was observed during early immune reconstitution in children undergoing allogeneic transplant of purified $\mathrm{CD}_{3}{ }^{+}$cells. $^{14}$ Because we can exclude that mature $\mathrm{T}$ cells have been cotransplanted with the ex vivo cultured $\mathrm{CD} 34^{+}$cells, the most likely explanation for the presence of phenotypically memory $\mathrm{T}$ cells is the survival of pre-existing, nontransduced circulating $\mathrm{T}$ cells, which were generated on enzyme replacement therapy. ${ }^{4}$ Indeed, at early followup, a substantial proportion of the circulating naive and memory T cells was nontransduced (Fig E3). Gene-corrected cells became the majority over time because of the selective advantage for $\mathrm{ADA}^{+} \mathrm{T}$ cells, possibly occurring during peripheral expansion and/or antigen-specific stimulation. 
A CD4 naïve

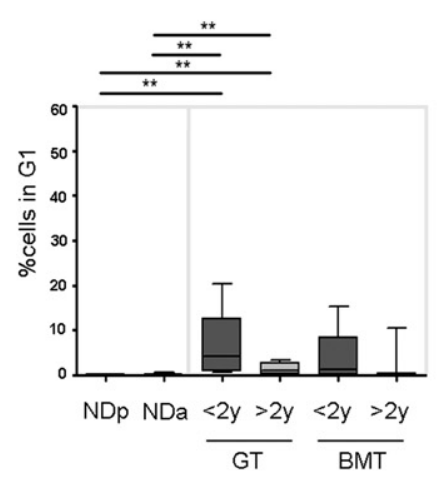

E CD8 naïve

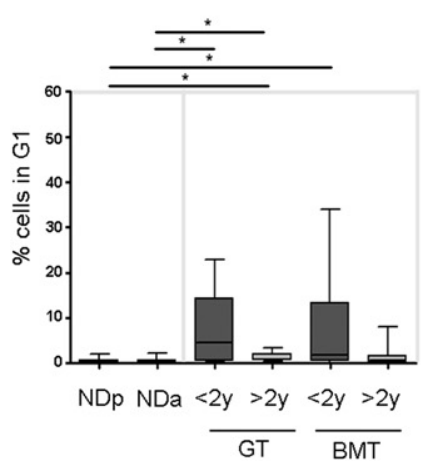

B

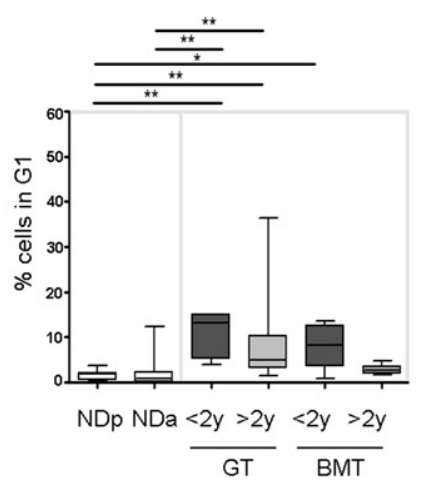

$\mathbf{F}$

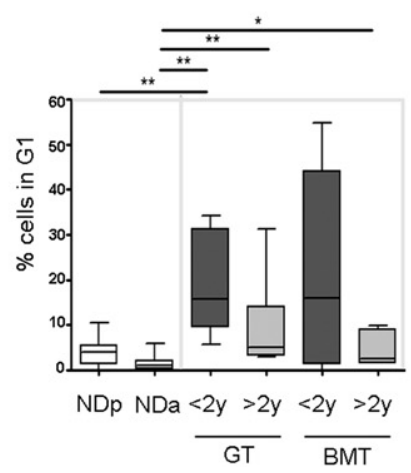

C

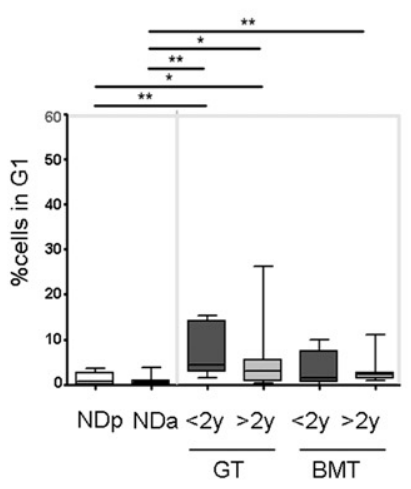

G

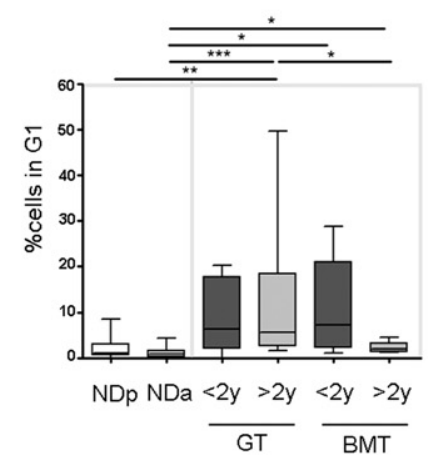

D

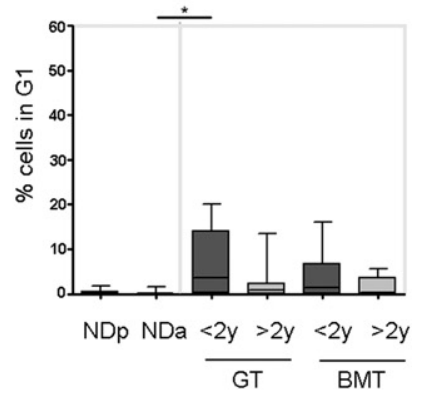

H

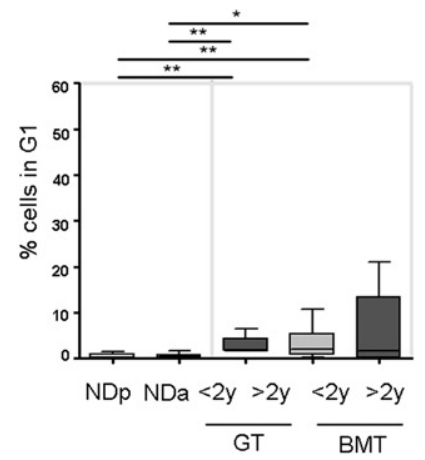

FIG 3. Cell cycle analysis reported as percentage of different T-cell subsets in $\mathrm{G} 1$ phase. Data refer to CD4 (A-D) and CD8 (E-H) naive, central memory (CM), effector memory (EM), and TEMRA T cells. Dark gray and light gray boxes indicate respectively early and late follow-up. Pediatric normal donors $(N D p), \mathrm{n}=11 ; \mathrm{GT}<2$ years, $\mathrm{n}=5 ; \mathrm{GT}>2$ years, $\mathrm{n}=9$; $\mathrm{BMT}<2$ years, $\mathrm{n}=7$; $\mathrm{BMT}>2$ years, $\mathrm{n}=7$. NDa, Adult normal donors.

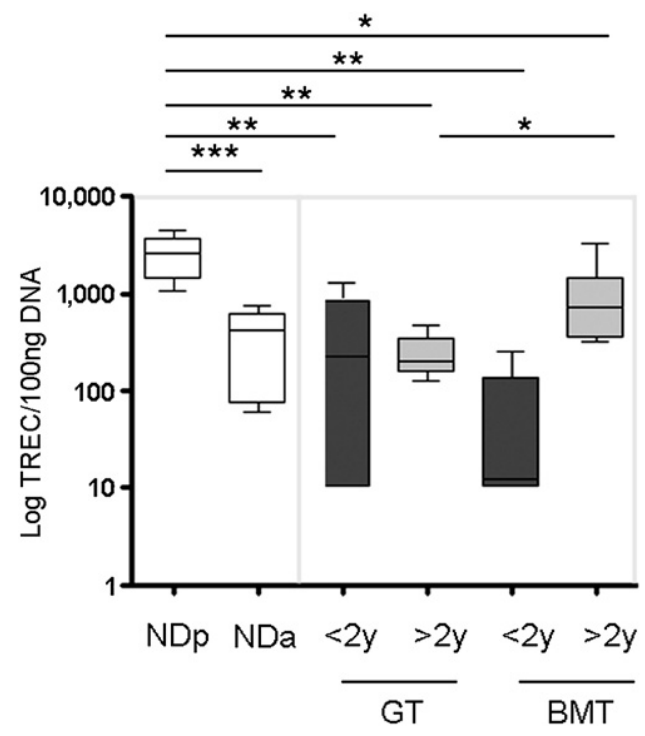

FIG 4. TREC content analysis in $\mathrm{CD}^{+}{ }^{+} \mathrm{CD} 45 \mathrm{RA}{ }^{+}$naive $T$ cells. Number of TREC molecules is reported as Log TREC/100 ng DNA. NDp, Pediatric normal donors $(\mathrm{n}=8) ; N D a$, adult normal donors. GT and BMT patients have been divided according to early $(<2$ years, $G T, n=5 ; B M T, n=5)$ and late ( $>2$ years, GT, $n=5$; BMT, $n=6$ ) follow-up.
Although the immune phenotype analysis was affected by a large intragroup variability, the relative distributions of memory cells were closer to the pattern observed in the adult rather than pediatric healthy controls for both the GT and BMT groups.

Human $\gamma \delta$ T cells represent a heterogeneous population of nonMHC-restricted cells involved in the early response to pathogens, ${ }^{29}$ in the lymphoid stress-surveillance response, sharing characteristics with the adaptive and innate immune responses ${ }^{30}$ particularly important early in life. ${ }^{31}$ Because patients with ADA-SCID show alterations in thymic function and architecture, ${ }^{32}$ the increase in $\gamma \delta$ T cells observed in the GT group could be related to the slow recovery of the thymic activity, implying a disadvantage in the $\alpha \beta$ TCR rearrangement. Moreover, the expression of CD $8 \alpha \alpha$, a marker associated with extrathymic differentiation, ${ }^{33,34}$ was not different across the considered study groups, indicating that after GT, like BMT, the immune reconstitution process is mainly thymus derived.

The combined cell cycle and immune phenotypic analysis revealed a higher percentage of cycling cells in the naive T-cell compartment from both the GT and BMT groups at early follow-up and a tendency to normalize at later time points. This suggests homeostatic proliferation as the substantial mechanism of T-cell repopulation in early phases after treatment, as described during lymphopenia. ${ }^{35}$ Other investigators have proposed that the rapid proliferation observed after BMT is mainly associated with the occurrence of GVDH and infection. ${ }^{36}$ In this regard, it is important to note that most GT patients did not experience infectious 
A

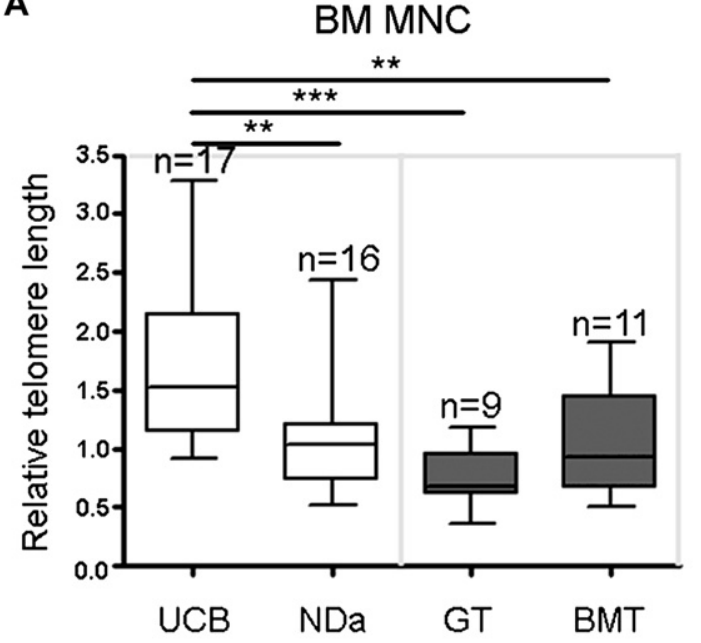

C
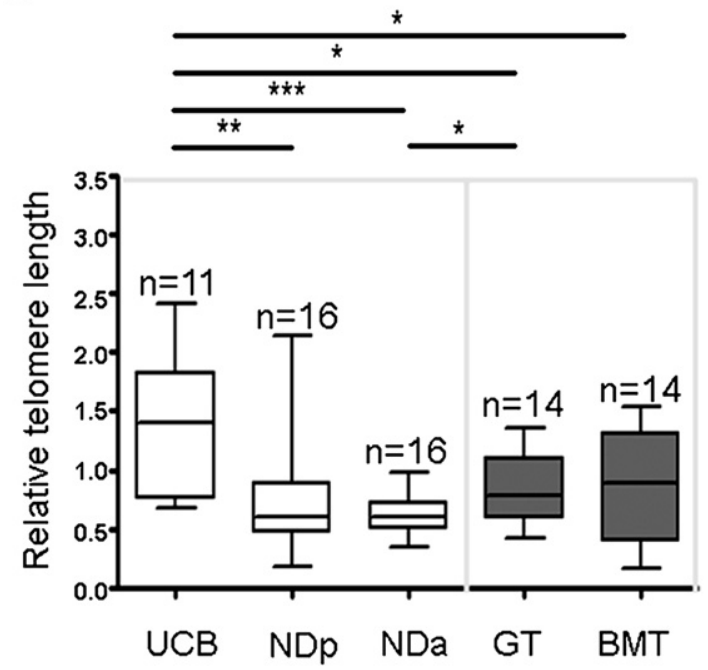

B

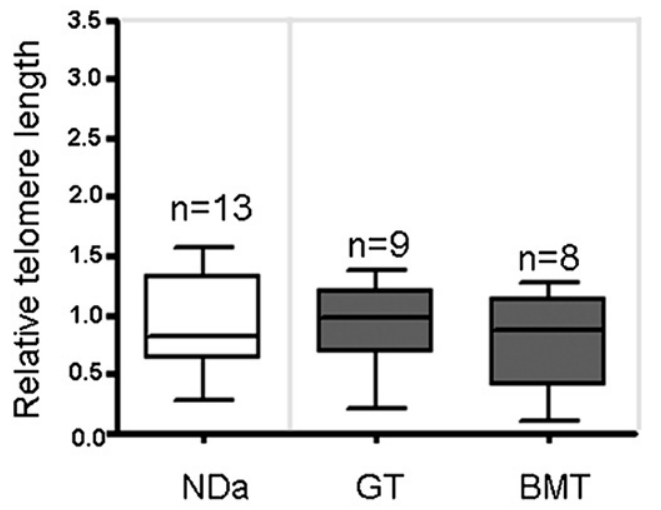

D $\quad$ PB CD3

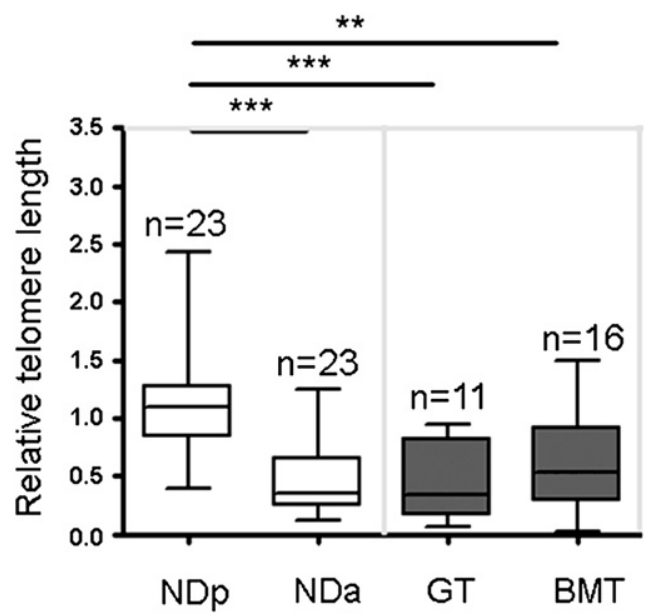

FIG 5. Telomere length analysis in the BM and PB compartments. The number of samples composing the different data sets is reported above the whiskers. In $C$, in the GT subset, 2 patients were included twice because they were analyzed at both early and late follow-up. BM MNC, Bone marrow mononuclear cells; $N D a$, adult normal donors; $N D p$, pediatric normal donors; $P B$, peripheral blood; UCB, umbilical cord blood.

complications, and the GVHD-related bias is unlikely to occur because of the autologous nature of the transplant. Importantly, our molecular studies on vector integration ${ }^{7,37,38}$ (and data not shown) and TCR-V $\beta$ repertoire analyses ${ }^{4}$ confirmed that the presence of a cycling population was not associated with clonal expansion.

Although the safety of GT has been widely studied in terms of genotoxicity, ${ }^{4,7}$ other relevant biological questions remain open. In particular, aging of the newly differentiating progeny has been suggested as a potential side effect after BMT, even if this point is still debated. ${ }^{18,39,40}$ In this regard, it has been hypothesized that cell senescence may be associated with the rapid expansion of engrafting HSCs aimed to repopulate the BM niches emptied by the conditioning regimen. Because during the gene transfer protocol procedures HSCs are manipulated in vitro and exposed to cytokines, this may increase the risk of premature senescence seen after standard BMT. According to our data, BM MNCs as well as BM and PB granulocytes of GT and BMTtreated patients did not show altered telomere length dynamics.
These data indicate that the gene transfer procedure does not induce cellular senescence of the progenitor compartment and are in agreement with the reported transient activation of the enzyme telomerase during in vitro stimulation of hematopoietic stem/ progenitor cells. ${ }^{41}$ Indeed, preliminary experiments did not show shortening of telomeres after in vitro cytokine stimulation of $\mathrm{CD} 34^{+}$cells (data not shown).

On the contrary, both BMT and GT patients' T cells showed shorter telomeres than pediatric controls, in the range of healthy adult donors. Thus, T-cell senescence, as reported by other studies after BMT, ${ }^{16,17}$ cannot be ascribed simply to the skewing of memory $\mathrm{T}$ cells after transplantation but also is a result of a specific reduction in the naive compartment, in accordance with their increased proliferation after treatment. Along the same lines is the observed reduction in TREC content in naive $\mathrm{T}$ cells with respect to normal pediatric donors as a consequence of cell proliferation and consequently TREC dilution. Naive $\mathrm{CD} 4^{+} \mathrm{T}$ cells are able to proliferate postthymically while retaining their naive 


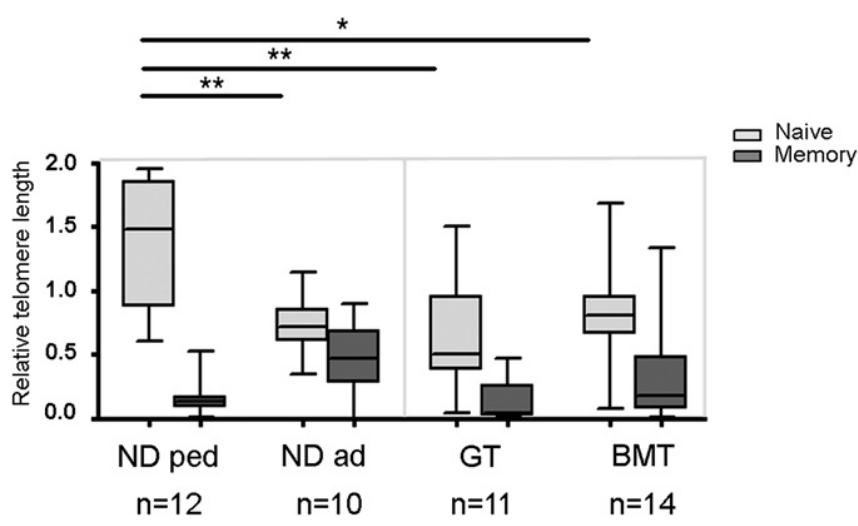

FIG 6. Telomere length analysis on naive and memory T cells. Naive (light gray) and memory (dark gray) T cells were isolated from adult and pediatric healthy donors, and from GT and BMT patients. Relative telomere length is reported. The number of samples composing each data set is reported. ND ad, Adult normal donors; ND ped, pediatric normal donors.

phenotype and functional characteristics, balancing by peripheral self-renewal the reduced output from the thymus in lymphopenic condition and aging. ${ }^{10,42-44}$ Our observation also supports the need for combining different markers (ie, TREC content and Ki67 expression) for a correct thymic output evaluation in human beings, as recently suggested by different authors. ${ }^{45,46}$

In summary, our data show that T-cell reconstitution after GT for ADA-SCID, like allogeneic BMT, is driven by de novo thymopoiesis, as well as by homeostatic expansion of naive and memory $\mathrm{T}$ cells, especially in the first months after treatment. The latter mechanism could explain the telomere shortening observed in $\mathrm{T}$ cells from both GT and BMT-treated patients, whereas normal telomere length in the myeloid and BM compartment indicates no difference between the autologous and allogeneic procedure at the stem/progenitor cell level.

Overall, the current study provides novel findings on the kinetic and different T-cell subset contribution to immune reconstitution after GT in patients with SCID and confirms GT as a valid alternative to BMT.

We acknowledge A. Palini for help in setting the protocol for the cell cycle analysis and all the Blood Bank staff of San Raffaele Hospital for their contribution to this study.

Clinical implications: Autologous transplantation of genecorrected hematopoietic stem/progenitor cells is a clinically valid alternative to BMT in terms of safety and efficacy of immune reconstitution for the cure of monogenic immune disorders.

\section{REFERENCES}

1. Cavazzana-Calvo M, Hacein-Bey S, de Saint Basile G, Gross F, Yvon E, Nusbaum $\mathrm{P}$, et al. Gene therapy of human severe combined immunodeficiency (SCID)-X1 disease. Science 2000;288:669-72.

2. Hacein-Bey-Abina S, Hauer J, Lim A, Picard C, Wang GP, Berry CC, et al. Efficacy of gene therapy for X-linked severe combined immunodeficiency. N Engl J Med 2010;363:355-64.

3. Gaspar HB, Parsley KL, Howe S, King D, Gilmour KC, Sinclair J, et al. Gene therapy of X-linked severe combined immunodeficiency by use of a pseudotyped gammaretroviral vector. Lancet 2004;364:2181-7.
4. Aiuti A, Cattaneo F, Galimberti S, Benninghoff U, Cassani B, Callegaro L, et al. Gene therapy for immunodeficiency due to adenosine deaminase deficiency. N Engl J Med 2009;360:447-58

5. Aiuti A, Slavin S, Aker M, Ficara F, Deola S, Mortellaro A, et al. Correction of ADA-SCID by stem cell gene therapy combined with nonmyeloablative conditioning. Science 2002;296:2410-3

6. Gaspar HB, Bjorkegren E, Parsley K, Gilmour KC, King D, Sinclair J, et al. Successful reconstitution of immunity in ADA-SCID by stem cell gene therapy following cessation of PEG-ADA and use of mild preconditioning. Mol Ther 2006;14: 505-13.

7. Aiuti A, Cassani B, Andolfi G, Mirolo M, Biasco L, Recchia A, et al. Multilineage hematopoietic reconstitution without clonal selection in ADA-SCID patients treated with stem cell gene therapy. J Clin Invest 2007;117:2233-40.

8. Qasim W, Gaspar HB, Thrasher AJ. Progress and prospects: gene therapy for inherited immunodeficiencies. Gene Ther 2009;16:1285-91.

9. Williams KM, Hakim FT, Gress RE. T cell immune reconstitution following lymphodepletion. Semin Immunol 2007;19:318-30.

10. Mackall CL, Fry TJ, Bare C, Morgan P, Galbraith A, Gress RE. IL-7 increases both thymic-dependent and thymic-independent $\mathrm{T}$-cell regeneration after bone marrow transplantation. Blood 2001;97:1491-7.

11. Min B, Paul WE. Endogenous proliferation: burst-like CD4 T cell proliferation in lymphopenic settings. Semin Immunol 2005;17:201-7.

12. Bubanovic IV. Crossroads of extrathymic lymphocytes maturation pathways. Med Hypotheses 2003;61:235-9.

13. de Vries E, van Tol MJ, van den Bergh RL, Waaijer JL, ten Dam MM, Hermans J, et al. Reconstitution of lymphocyte subpopulations after paediatric bone marrow transplantation. Bone Marrow Transplant 2000;25:267-75.

14. Eyrich M, Leiler C, Lang P, Schilbach K, Schumm M, Bader P, et al. A prospective comparison of immune reconstitution in pediatric recipients of positively selected CD34+ peripheral blood stem cells from unrelated donors vs recipients of unmanipulated bone marrow from related donors. Bone Marrow Transplant 2003;32: 379-90.

15. Sarzotti-Kelsoe M, Win CM, Parrott RE, Cooney M, Moser BK, Roberts JL, et al. Thymic output, T-cell diversity, and T-cell function in long-term human SCID chimeras. Blood 2009;114:1445-53.

16. Wynn R, Thornley I, Freedman M, Saunders EF. Telomere shortening in leucocyte subsets of long-term survivors of allogeneic bone marrow transplantation. $\mathrm{Br}$ J Haematol 1999;105:997-1001.

17. Akiyama M, Asai O, Kuraishi Y, Urashima M, Hoshi Y, Sakamaki H, et al. Shortening of telomeres in recipients of both autologous and allogeneic hematopoietic stem cell transplantation. Bone Marrow Transplant 2000;25:441-7.

18. Awaya N, Baerlocher GM, Manley TJ, Sanders JE, Mielcarek M, Torok-Storb B, et al. Telomere shortening in hematopoietic stem cell transplantation: a potential mechanism for late graft failure? Biol Blood Marrow Transplant 2002;8:597-600.

19. Lucarelli G, Gaziev J. Advances in the allogeneic transplantation for thalassemia. Blood Rev 2008;22:53-63.

20. Chiesa R, Cappelli B, Crocchiolo R, Frugnoli I, Biral E, Noe A, et al. Unpredictability of iv Busulfan pharmacokinetics in children undergoing hematopoietic stem cell transplant for advanced beta thalassemia: limited toxicity with a dose adjustment policy. Biol Blood Marrow Transplant 2009;16:622-8.

21. Gerdes J, Lemke H, Baisch H, Wacker HH, Schwab U, Stein H. Cell cycle analysis of a cell proliferation-associated human nuclear antigen defined by the monoclonal antibody Ki-67. J Immunol 1984;133:1710-5.

22. Scholzen T, Gerdes J. The Ki-67 protein: from the known and the unknown. J Cell Physiol 2000;182:311-22.

23. Konno A, Okada K, Mizuno K, Nishida M, Nagaoki S, Toma T, et al. CD8alpha alpha memory effector $\mathrm{T}$ cells descend directly from clonally expanded CD8alpha + beta high TCRalpha beta T cells in vivo. Blood 2002;100:4090-7.

24. Cawthon RM. Telomere measurement by quantitative PCR. Nucleic Acids Res 2002;30:e47.

25. Guazzi V, Aiuti F, Mezzaroma I, Mazzetta F, Andolfi G, Mortellaro A, et al. Assessment of thymic output in common variable immunodeficiency patients by evaluation of T cell receptor excision circles. Clin Exp Immunol 2002;129:346-53.

26. Sallusto F, Geginat J, Lanzavecchia A. Central memory and effector memory T cell subsets: function, generation, and maintenance. Annu Rev Immunol 2004;22: 745-63.

27. Ghia P, Prato G, Stella S, Scielzo C, Geuna M, Caligaris-Cappio F. Age-dependent accumulation of monoclonal $\mathrm{CD} 4+\mathrm{CD} 8+$ double positive $\mathrm{T}$ lymphocytes in the peripheral blood of the elderly. Br J Haematol 2007;139:780-90.

28. Comans-Bitter WM, de Groot R, van den Beemd R, Neijens HJ, Hop WC, Groeneveld $\mathrm{K}$, et al. Immunophenotyping of blood lymphocytes in childhood: reference values for lymphocyte subpopulations. J Pediatr 1997;130:388-93.

29. Roark CL, Simonian PL, Fontenot AP, Born WK, O'Brien RL. gammadelta T cells: an important source of IL-17. Curr Opin Immunol 2008;20:353-7. 
30. Hayday AC. Gammadelta T cells and the lymphoid stress-surveillance response. Immunity 2009;31:184-96.

31. De Rosa SC, Andrus JP, Perfetto SP, Mantovani JJ, Herzenberg LA, Herzenberg LA, et al. Ontogeny of gamma delta T cells in humans. J Immunol 2004;172: 1637-45.

32. Poliani PL, Facchetti F, Ravanini M, Gennery AR, Villa A, Roifman CM, et al Early defects in human T-cell development severely affect distribution and maturation of thymic stromal cells: possible implications for the pathophysiology of Omenn syndrome. Blood 2009;114:105-8.

33. Torfadottir H, Freysdottir J, Skaftadottir I, Haraldsson A, Sigfusson G, Ogmundsdottir HM. Evidence for extrathymic T cell maturation after thymectomy in infancy. Clin Exp Immunol 2006;145:407-12.

34. Hayday A, Gibbons D. Brokering the peace: the origin of intestinal T cells. Mucosal Immunol 2008;1:172-4.

35. Eyrich M, Wollny G, Tzaribaschev N, Dietz K, Brugger D, Bader P, et al. Onset of thymic recovery and plateau of thymic output are differentially regulated after stem cell transplantation in children. Biol Blood Marrow Transplant 2005;11: 194-205.

36. Hazenberg MD, Otto SA, de Pauw ES, Roelofs H, Fibbe WE, Hamann D, et al T-cell receptor excision circle and T-cell dynamics after allogeneic stem cell transplantation are related to clinical events. Blood 2002;99:3449-53.

37. Cassani B, Montini E, Maruggi G, Ambrosi A, Mirolo M, Selleri S, et al. Integration of retroviral vectors induces minor changes in the transcriptional activity of $\mathrm{T}$ cells from ADA-SCID patients treated with gene therapy. Blood 2009;114:3546-56.

38. Biasco L, Ambrosi A, Pellin D, Bartholomae C, Brigida I, Roncarolo MG, et al Integration profile of retroviral vector in gene therapy treated patients is cell- specific according to gene expression and chromatin conformation of target cell EMBO Mol Med 2011;3:89-101.

39. Akiyama M, Hoshi Y, Sakurai S, Yamada H, Yamada O, Mizoguchi H. Changes of telomere length in children after hematopoietic stem cell transplantation. Bone Marrow Transplant 1998;21:167-71.

40. de Pauw ES, Otto SA, Wijnen JT, Vossen JM, van Weel MH, Tanke HJ, et al Long-term follow-up of recipients of allogeneic bone marrow grafts reveals no progressive telomere shortening and provides no evidence for haematopoietic stem cell exhaustion. Br J Haematol 2002;116:491-6.

41. Chiu CP, Dragowska W, Kim NW, Vaziri H, Yui J, Thomas TE, et al. Differentia expression of telomerase activity in hematopoietic progenitors from adult human bone marrow. Stem Cells 1996;14:239-48.

42. Kimmig S, Przybylski GK, Schmidt CA, Laurisch K, Mowes B, Radbruch A, et al. Two subsets of naive $\mathrm{T}$ helper cells with distinct $\mathrm{T}$ cell receptor excision circle content in human adult peripheral blood. J Exp Med 2002;195:789-94.

43. Kohler S, Thiel A. Life after the thymus: CD31+ and CD31- human naive CD4+ T-cell subsets. Blood 2009;113:769-74.

44. Junge S, Kloeckener-Gruissem B, Zufferey R, Keisker A, Salgo B, Fauchere JC, et al. Correlation between recent thymic emigrants and CD31+ (PECAM-1) $\mathrm{CD} 4+\mathrm{T}$ cells in normal individuals during aging and in lymphopenic children. Eur J Immunol 2007;37:3270-80.

45. Bains I, Thiebaut R, Yates AJ, Callard R. Quantifying thymic export: combining models of naive $\mathrm{T}$ cell proliferation and TCR excision circle dynamics gives an explicit measure of thymic output. J Immunol 2009;183:4329-36.

46. Hazenberg MD, Borghans JA, de Boer RJ, Miedema F. Thymic output: a bad TREC record. Nat Immunol 2003;4:97-9. 


\section{METHODS}

\section{Proliferation and cell cycle analysis}

Blood samples $(100 \mu \mathrm{L})$ were stained with the antibodies anti-CD4 or CD8 phycoerythrin-Cy7, CD62L-phycoerythrin, CD45RA-PerCp-Cy5.5, and CD45RO-APC (all from Becton Dickinson, San Diego, Calif, except the anti-CD45RA-PerCp-Cy5.5 which was from Biolegend, San Diego, Calif), 15 minutes at room temperature. After red blood cell lysis, cells were washed, fixed with Cytofix/Cytoperm solution, and permeabilized with Perm/Wash solution (both from Becton Dickinson, used according to the manufacturer's instructions). Cells in the G1 phase were identified by Ki67 staining, performed using anti Ki67-FITC or $\operatorname{IgG}_{1 \mathrm{k}}$-FITC (catalog no. 556026 by Becton Dickinson) 25 minutes at room temperature. Before washing, samples were incubated for an additional 5 minutes with Vybrant Violet (Invitrogen, Carlsbad, Calif) diluted 1:100. Samples were then washed and analyzed with a BD-LSR II Flow Cytometer (Becton Dickinson).

\section{Telomere length quantification}

Telomere length quantification was performed by the qPCR approach, using 36B4 as the normalizing gene.

Primers were as follows: Tellb:5'-CGGTTTGTTTGGGTTTGGGTT TGGGTTTGGGTTTGGGTT-3'; Tel2b:5'-GGCTTGCCTTACCCTTACCC TTACCCTTACCCTTACCCT-3'; 36B4d:5'-CCCATTCTATCATCAACGGG
TACAA-3'; 36B4u:5'-CAGCAAGTGGGAAGGTGTAATCC-3'. The composition of the reaction mix was as follows: genomic DNA (15 ng), $12.5 \mu \mathrm{L}$ SybrGreen 2x mastermix (ABI Applied Biosystems Inc, Foster City, Calif), primers: Tel1b $100 \mathrm{nmol} / \mathrm{L}$ and Tel2b $900 \mathrm{nmol} / \mathrm{L}$ (or 36B4d $500 \mathrm{nmol} / \mathrm{L}$ and $36 \mathrm{~B} 4 \mathrm{u} 300 \mathrm{nmol} / \mathrm{L}$ ), water to $25 \mu \mathrm{L}$.

Thermal profiles were as follows: Tel plate: $95^{\circ} \mathrm{C} 10^{\prime} ; 96^{\circ} \mathrm{C} 10$ "; 45 cycles of $95^{\circ} \mathrm{C} 15^{\prime}, 54^{\circ} \mathrm{C} 1$ '; final dissociation stage; $36 \mathrm{~B} 4$ plate: $95^{\circ} \mathrm{C} 5^{\prime}$; 45 cycles of $95^{\circ} \mathrm{C} 15^{\prime}, 58^{\circ} \mathrm{C} 1$ '; final dissociation stage. The quality of the qPCR amplification was tested by considering the slope of the standard curve (between -3 and -3.6), the $R^{2}(>0.98)$ and the dissociation curve. Telomere length was calculated with the $2^{-\Delta \Delta \mathrm{Ct}}$ method. In each plate, a sample derived from a stock of human PBMCs was used as a reference, allowing the comparison between different runs.

\section{Isolation of different peripheral blood cell subsets}

After Ficoll-Hypaque MNC separation, $\mathrm{CD}^{+}$, naive, and memory T cells and $\mathrm{CD} 15^{+}$cells were purified with magnetic beads isolation. $\mathrm{CD}^{+}$and $\mathrm{CD} 15^{+}$were isolated by positive selection (purity more than $95 \%$ ). For the naive and memory T-cell separation, after $\mathrm{CD} 3$ isolation by negative selection, the $\mathrm{CD} 45 \mathrm{RA}^{+}$and $\mathrm{CD} 45 \mathrm{RO}^{+}$cells were isolated by positive selection (purity more than $80 \%$ for both naive and memory cells). All isolation kits and columns were purchased from Miltenyi Biotec, Auburn, Calif. 
Gate: naive

Gate: CD4 or CD8

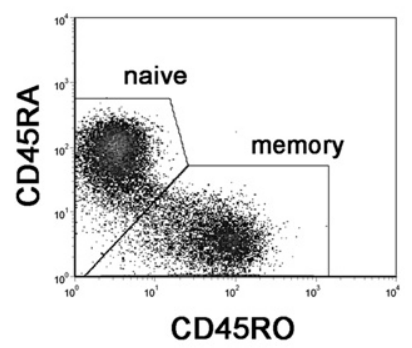

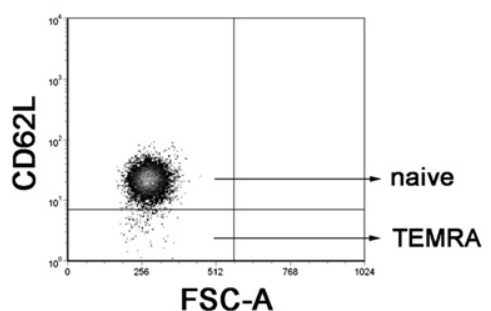

Gate: memory

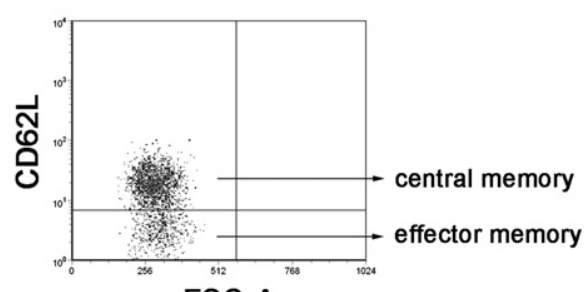

FSC-A

FIG E1. Fluorescence-activated cell sorting analysis showing the gating strategy applied for T-cell immunophenotypic and cell cycle analysis. The analysis was performed on both $\mathrm{CD}^{+}{ }^{+}$and $\mathrm{CD} 8^{+}$cells separately. After gating in either CD45RA ${ }^{+}$or $\mathrm{CD} 45 \mathrm{RO}^{+}$cells, naive, central memory (CM), effector memory (EM), and TEMRA cells were distinguished according to CD62L expression. In each population, the percentage of cycling cells has been calculated on the basis of the expression of Ki67. The plots refer to a representative healthy donor after gating on $\mathrm{CD} 4^{+}$cells. For the sake of simplicity, only 1 representative plot showing the Ki67 staining is reported, but the analysis was performed on naive, central memory, effector memory, and TEMRA populations for both $\mathrm{CD}^{+}$and $\mathrm{CD}^{+} \mathrm{T}$ cells. 

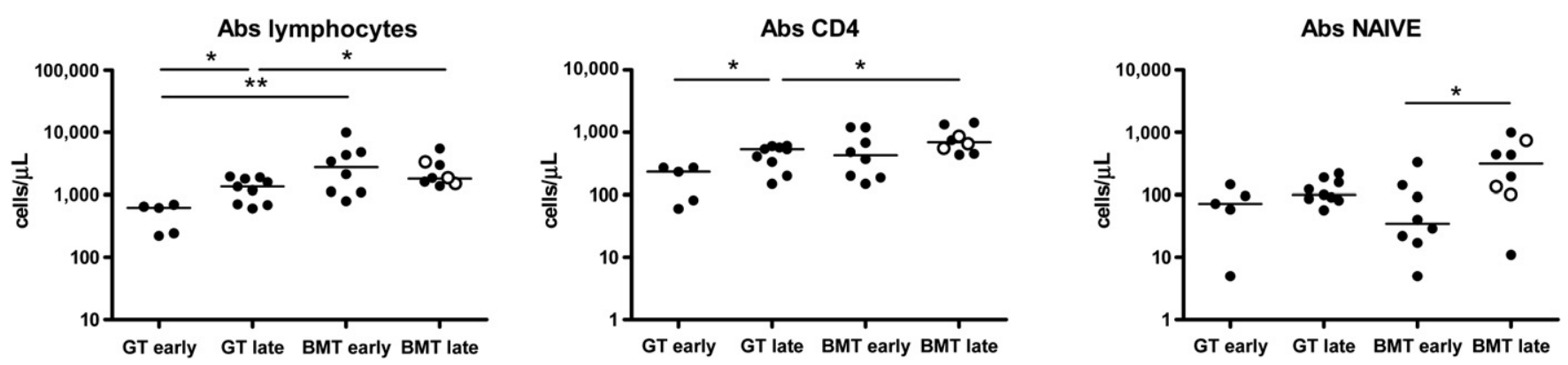

FIG E2. Absolute lymphocyte counts of GT and BMT-treated patients at early and late follow-up. Total lymphocyte, total $\mathrm{CD}^{+}$, and naive $\mathrm{CD} 4^{+} \mathrm{T}$-cell subsets are reported. Patients with ADA-SCID undergoing BMT are represented as empty circles in the BMT group. Even if the small number of patients does not allow statistical analysis, BMT patients with ADASCID do not tend to segregate from other BMT patients. Counts are reported as absolute number of cells $/ \mu \mathrm{L}$. ${ }^{*} P=.05 ;{ }^{*} P=.005$. 


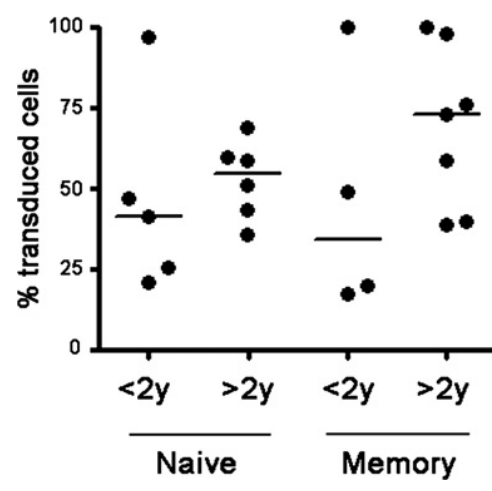

FIG E3. Transduced cells quantification on naive and memory $T$ cells from GT patients. The percentage of transduced cells is calculated on the basis of the amplification of the sequence coding for the resistance to Neomicin carried by the integrated vector. Dots represent single samples, and the horizontal line indicates the median value. Data are divided according to early and late follow-up and indicate the contribution of transduced cells to the $2 \mathrm{~T}$-cell subsets during immune reconstitution. 
CD4 naive GT

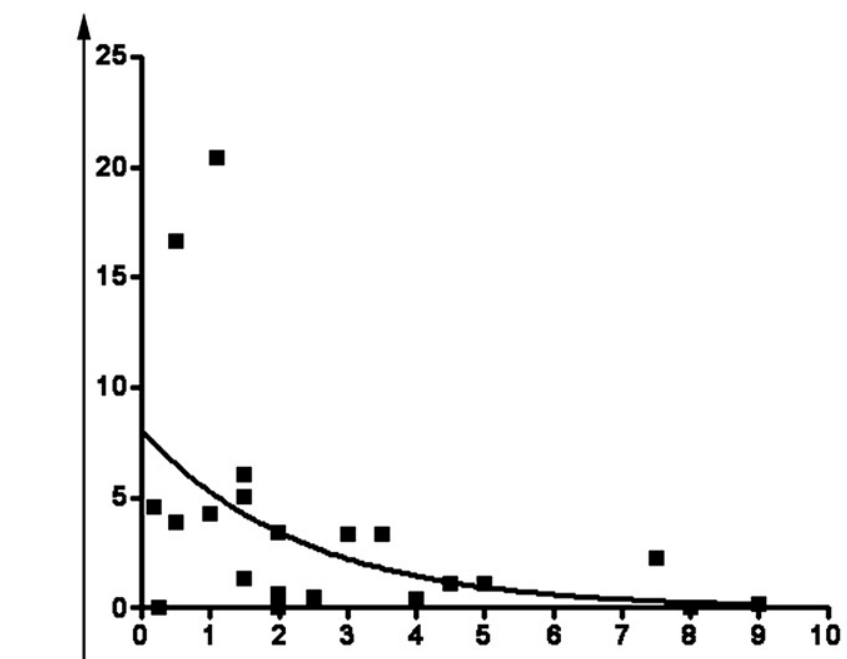

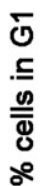

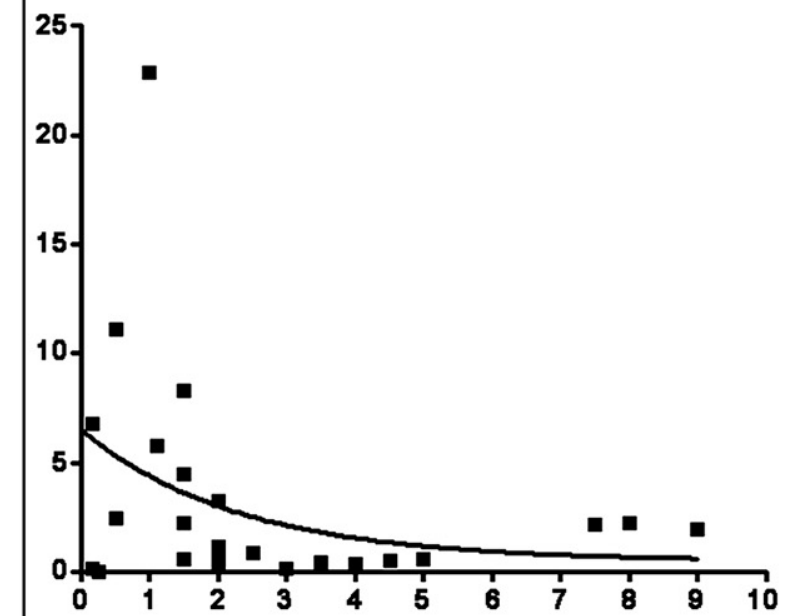

CD4 naive BMT

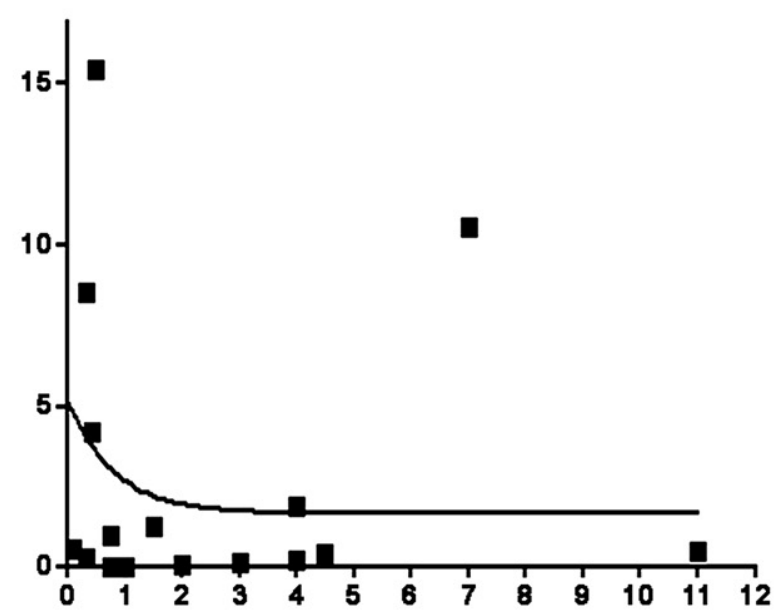

CD8 naive BMT

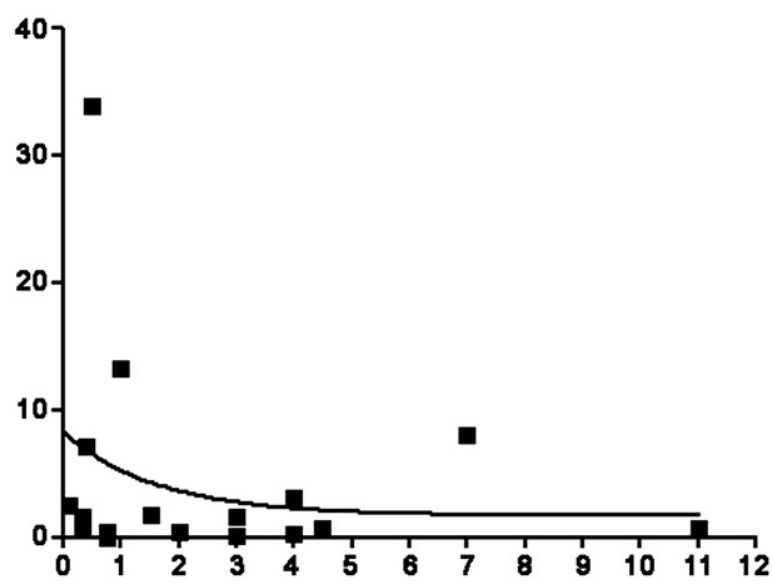

\section{FU (years)}

FIG E4. Variation of the percentage of cells in the G1 phase at different follow-up (FU) for GT and BMT patients. Data from the naive compartment only is shown in the graph. Dots represent all the time points analyzed for all the patients available. The line has been calculated as exponential decay to underline the tendency to decrease the percentage of cycling cells at late follow-up. 
CD4 naive

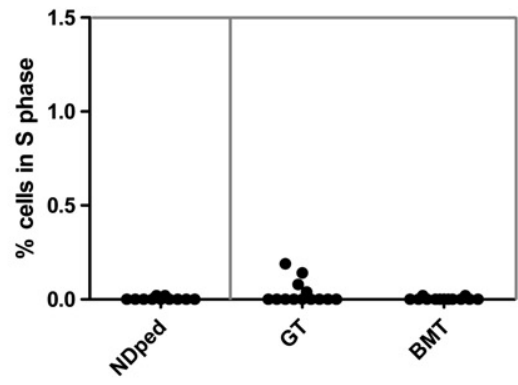

CD4 effector memory

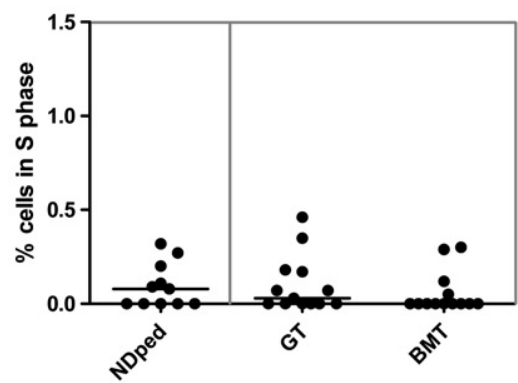

CD8 naive

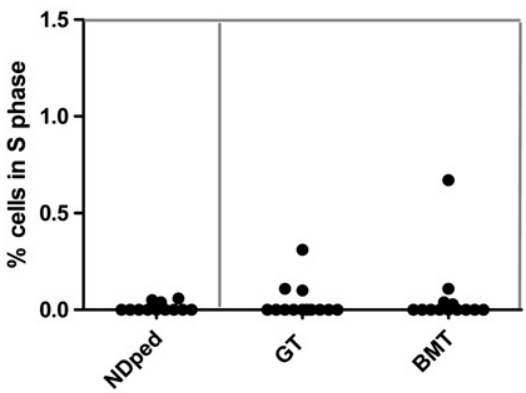

CD8 effector memory

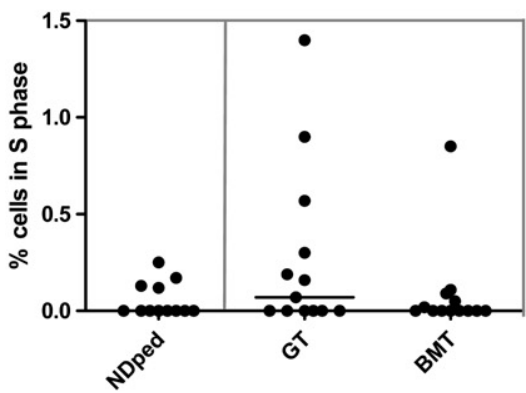

CD4 central memory

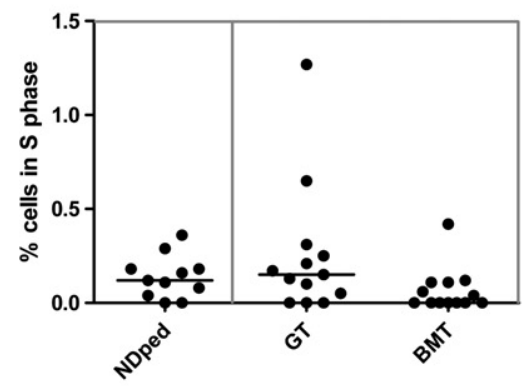

CD4 TEMRA

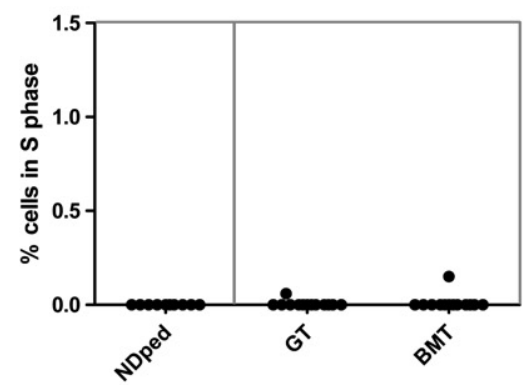

CD8 central memory

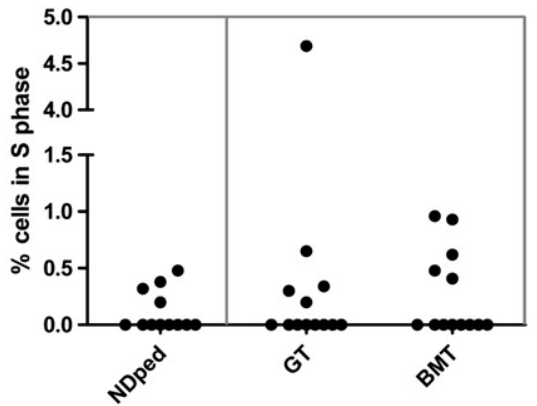

CD8 TEMRA

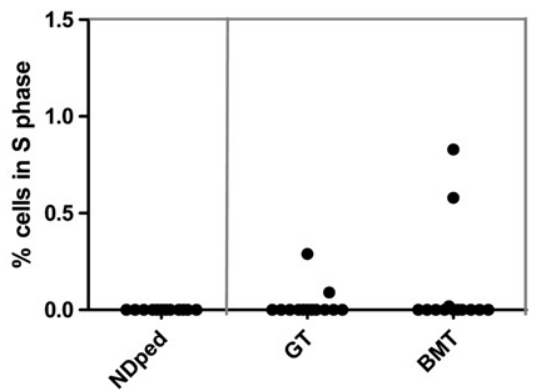

FIG E5. S/G2/M phase analysis on the different T-cell subsets. Percentage of cells in S/G2/M phase (positive for Ki67 and showing double Vybrant Vyolet signal) are reported for the different T-cell subsets of pediatric normal donors (NDped) and BMT and GT-treated patients. In the GT group, 1 patient has been considered at both early and late follow-up. No statistically significant difference can be detected between the study groups. NDped, $\mathrm{n}=11$; BMT group, $\mathrm{n}=13 ;$ GT group, $\mathrm{n}=13$. 
TABLE E1. Patients' characteristics

\begin{tabular}{|c|c|c|c|c|}
\hline Patient group & Diagnosis & $\begin{array}{l}\text { Total no. of } \\
\text { analyzed patients }\end{array}$ & Treatment & $\begin{array}{l}\text { Follow-up at analysis } \\
\text { (years posttransplantation) }\end{array}$ \\
\hline$<2$ y BMT & $\beta$-Thalassemia $(n=7), \operatorname{SCID}(n=1)$ & 8 & HLA-identical BMT & $0.7(0.3-1.2)$ \\
\hline$>2$ y BMT & $\begin{array}{l}\beta \text {-Thalassemia }(n=2), \text { ADA-SCID }(n=3), \\
\operatorname{SCID}(n=1), \operatorname{IPEX}(\mathrm{n}=1), \operatorname{CGD}(\mathrm{n}=1)\end{array}$ & 8 & HLA-identical BMT & $3.9(2-10)$ \\
\hline$<2$ y GT & ADA-SCID & 5 & GT & $1(1-1.8)$ \\
\hline$>2$ y GT & ADA-SCID & 9 & GT & $3(2-8.5)$ \\
\hline
\end{tabular}

$C G D$, Chronic granulomatous disease; IPEX, X-linked immunodeficiency, polyendocrinopathy, enteropathy.

Characteristics of the different study groups at the time of analysis. Median time point follow-up and range is indicated for each group. 


\begin{tabular}{|c|c|c|c|c|c|c|c|c|c|c|c|c|c|c|c|}
\hline \multicolumn{2}{|c|}{ Naive $<2$ y } & \multicolumn{2}{|c|}{ Naive $>2$ y } & \multicolumn{2}{|c|}{$\mathrm{CM}<2 \mathrm{y}$} & \multicolumn{2}{|c|}{$\mathrm{CM}>2 \mathrm{y}$} & \multicolumn{2}{|c|}{$\mathrm{EM}<2 \mathrm{y}$} & \multicolumn{2}{|c|}{$E M>2 y$} & \multicolumn{2}{|c|}{ TEMRA $<2 y$} & \multicolumn{2}{|c|}{ TEMRA $>2 y$} \\
\hline BMT & GT & BMT & GT & BMT & GT & BMT & GT & BMT & GT & BMT & GT & BMT & GT & BMT & GT \\
\hline $0.58 \pm 1.73$ & $1.07 \pm 0.61$ & $0.69 \pm 0.14$ & $0.44 \pm 0.21$ & $2.98 \pm 11.9$ & $3.65 \pm 1.40$ & $4.74 \pm 0.82$ & $5.11 \pm 2.71$ & $1.88 \pm 3.40$ & $1.84 \pm 1.35$ & $2.54 \pm 1.18$ & $1.04 \pm 1.33$ & $0.06 \pm 0.10$ & $0.08 \pm 0.30$ & $0.08 \pm 0.06$ & $0.14 \pm 0.08$ \\
\hline \multicolumn{16}{|c|}{ CD8 } \\
\hline \multicolumn{2}{|c|}{ Naive $<2$ y } & \multicolumn{2}{|c|}{ Naive $>2 y$} & \multicolumn{2}{|c|}{$\mathrm{CM}<2 \mathrm{y}$} & \multicolumn{2}{|c|}{$\mathrm{CM}>2 \mathrm{y}$} & \multicolumn{2}{|c|}{$\mathrm{EM}<2 \mathrm{y}$} & \multicolumn{2}{|c|}{$E M>2 y$} & \multicolumn{2}{|c|}{ TEMRA $<2 y$} & \multicolumn{2}{|c|}{ TEMRA $>2 y$} \\
\hline BMT & GT & BMT & GT & BMT & GT & BMT & GT & BMT & GT & BMT & GT & BMT & GT & BMT & GT \\
\hline $3.44 \pm 2.16$ & $0.35 \pm 2.19$ & $1.17 \pm 0.20$ & $0.44 \pm 0.21$ & $4.75 \pm 4.36$ & $0.32 \pm 0.96$ & $1.12 \pm 0.25$ & $0.83 \pm 0.35$ & $9.29 \pm 13.3$ & $0.95 \pm 1.40$ & $1.74 \pm 0.81$ & $2.42 \pm 2.93$ & $2.10 \pm 3.58$ & $0.20 \pm 0.42$ & $0.53 \pm 0.11$ & $0.71 \pm 0.43$ \\
\hline
\end{tabular}

$C M$, Central memory; $E M$, effector memory.

Absolute count of Ki67 $7^{+}$lymphocyte/ $\mu \mathrm{L}$ blood in the different T-cell subsets (median values). SE is indicated below each count. 